\title{
A nonrecoverable learning deficit
}

\author{
DAVID G. LAVOND, DAVID A. McCORMICK, and RICHARD F. THOMPSON \\ Stanford University, Stanford, California
}

\begin{abstract}
We have used classical conditioning of the rabbit nictitating membrane (NM)/eyelid response to study the neuronal basis of basic associative learning and memory. Unilateral lesions of the dorsolateral interpositus nucleus of the cerebellum abolish the learned response and prevent learning on the side of the lesion, but do not prevent performance of the unlearned reflex or learning on the contralateral side. Recovery of function of the learned NM/eyelid response does not occur after extensive training or retraining, after extensive recovery and training over periods of several months, after treatment with amphetamine, or after successfully learning a conditioned heart-rate response. The deficit would seem to be permanent.
\end{abstract}

For the past 15 years, we have focused on brain substrates of basic associative learning. We adopted classical conditioning in part because of the greater control over the stimuli and behaviors used in conditioning than is possible in operant situations. Lashley's (1950) failure to find the engram-the essential neuronal plasticity or changes necessary for the learning and memory of a specific behaviormay be attributed in part to the difficulty of controlling and isolating stimuli and behaviors in more complex operant and instrumental situations. Thus, it is much easier to determine with classical conditioning if the post-brain-injury behavioral deficit is caused by a general motor impairment by assessing both the conditioned and the reflexive behaviors. It is also easier to determine if the lack of behavior is due to loss of sensory capacities or lack of motivation by training on alternative behaviors.

In this brief paper, we first overview the current status of our search for the memory trace and then focus on results indicating that destruction of an essential part of the memory trace circuit in the cerebellum results in permanent and nonrecoverable abolition of the learned response. (By "memory trace circuit," we mean the neurons necessary for learning and performance of the learned response.) R. F. Thompson et al. (1976) chose classical conditioning of the rabbit nictitating membrane (NM)/eyelid response in part because of the extensive parametric behavioral studies on the preparation by Gormezano and his associates (Gormezano, 1972; Gormezano, Schneiderman, Deaux, \& Fuentes, 1962). In this

The work described in this article was supported in part by NSF Grants BNS 81-06648 and BNS 81-17115 and ONR Grant N0001483-K-0238 to R.F.T.; by NIMH Postdoctoral Fellowship 2F32 MH08233-03 to D.G.L.; and by NIMH Predoctoral Fellowship 5F31 MH08673-02 to D.A.M. D. G. Lavond and R. F. Thompson's mailing address is: Department of Psychology, Building 420, Jordan Hall, Stanford University, CA 94305. D. A. McCormick's current address is: Department of Neurology, Stanford University Medical Center, Stanford, CA 94305. paradigm, a rabbit is presented with a conditioning tone CS followed by a corneal airpuff UCS (typical parameters: CS $350 \mathrm{msec}$ in duration, $1 \mathrm{kHz}$ in frequency, and $85 \mathrm{~dB}$ in intensity; UCS intensity $2.1 \mathrm{~N} /$ $\mathrm{cm}^{2}, 100 \mathrm{msec}$ in duration). Both the CS and UCS terminate simultaneously, so that they overlap during the last $100 \mathrm{msec}$ and the CS onset precedes UCS onset by $250 \mathrm{msec}$. This relationship is described as simple delayed conditioning. The response can be measured by a minitorque potentiometer as the "thirdeyelid"-the nictitating membrane or NM-extends in a temporal direction over the eyeball. At the same time, the external eyelids close, and this can be measured easily with EMG recordings. The two measures, NM extension and external eyelid closure, correlate almost perfectly $(r=.98)$ over the course of learning (McCormick, Lavond, \& R. F. Thompson, 1982). Typically, rabbits are trained with $100-120$ pairings per day, and learn to a criterion of eight conditioned responses (CRs) in nine consecutive trials in about 1 day. Typically, the animals can be overtrained on the task in 2 days. In some of our studies, we have used an incandescent light bulb for a visual CS and have found comparable conditioning.

Our recent efforts have been directed toward brainstem mechanisms of classical conditioning, since the essential memory trace circuitry appears to be below the level of the thalamus. Thus, Enser (1976) reported that rabbits can learn simple delay NM conditioning with removal of all tissue above the level of the caudal thalamus, and Norman, Villablanca, Brown, Schwafel and Buchwald (1974) reported eyelid conditioning in decerebrate cats. We began with a survey of recordings-a brainstem mapping study (McCormick, Lavond, Donegan, \& R. F. Thompson, 1982; McCormick, Lavond, \& R. F. Thompson, 1983). Multiple-unit clusters were recorded from over 300 regions throughout the brainstem in well-trained rabbits. The kinds of relationships seen in the recordings identified areas with auditory evoked responses, airpuff evoked responses, and several classes of motor 
responses that differed in latency of the unit response with respect to the measured behavioral response. Figure 1 shows an example of a recording from cells of the lateral interpositus medial dentate nuclear region of the cerebellum. It is interesting to note that in this example there appear auditory-evoked onset responses as well as increases of unit firing that appear to predict the amplitude-time course (i.e., "model") of the learned NM/eyelid response but not the unlearned reflexive component. In some animals, this neuronal "model" precedes the learned behavioral response by as much as $50-60 \mathrm{msec}$.

Recording studies can indicate whether, and perhaps even how, a brain structure is involved in learning but do not themselves indicate whether that region is merely related or is sufficient and essential for learning. Thus, we began a series of lesion studies of the role of the cerebellum in conditioning (Clark et al., 1982; Clark, McCormick, Lavond, \& R. F. Thompson, 1984; Lavond, McCormick, Clark, Holmes, \& R. F. Thompson, 1981; McCormick, Clark, Lavond, \& R. F. Thompson, 1982; McCormick, Guyer, \& R. F. Thompson, 1982; McCormick et al., 1981; see also Yeo, Hardiman, Glickstein, \& Russell, 1982). As shown in Figure 2, unilateral lesion of the cerebellum or its major output system have a remarkable effect. The learned response is abolished unilaterally; however, the lesion does not prevent the rabbit from making a reflexive NM response or from learning the CR rapidly with the other eye (McCormick et al., 1981). In another study, we lesioned the cerebellum unilaterally before training the animals (Lincoln, McCormick, \& R. F. Thompson, 1982). These rabbits were incapable of learning on the side of the lesion despite extensive training. However, they learned normally when trained with the eye on the unlesioned side. It is possible, on the basis of these studies, to conclude that the lesion could not have affected such unitary phenomena as motivation, because the animals were still capable of learning the same task with the opposite NM/eyelid.

Our finding that the neuronal circuit necessary for expression of the learned behavioral response can be separated from the circuitry necessary for the reflexive response was most fortunate. This circuitry for the learned behavior now is known to exit through the superior cerebellar peduncle (Lavond et al., 1981; McCormick, Guyer, \& R. E. Thompson, 1982) and cross to the opposite red nucleus (Haley, Lavond, \& R. F. Thompson, 1983). Lesions of the superior cerebellar peduncle selectively abolish the learned, but not the unlearned, response. Electrolytic lesions

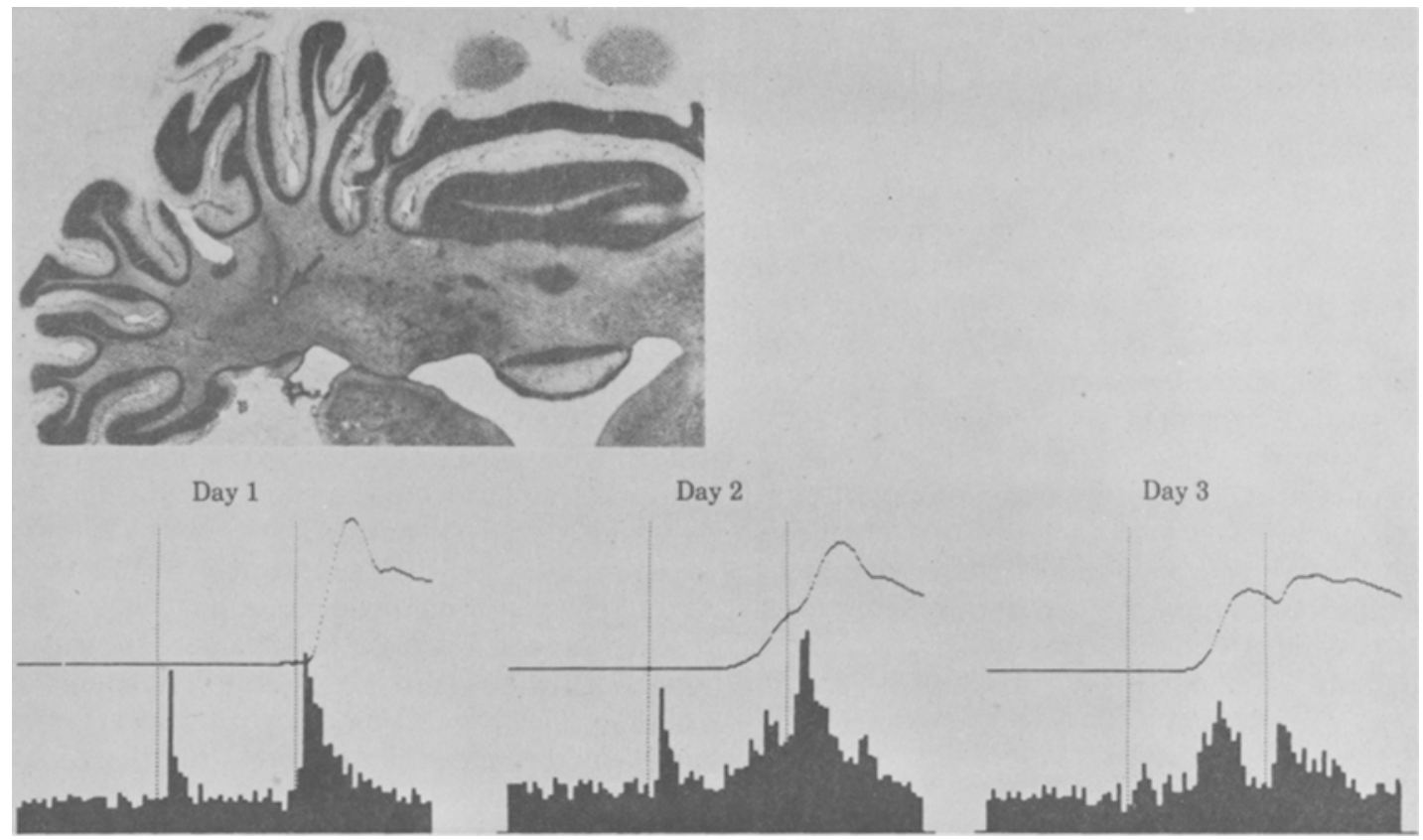

Figure 1. Histology of the position of a multiple-unit recording electrode within the deep cerebellar nuclei and peristimulus histograms of the unit activity early, middle, and late in training. Each histogram is a summation of the intratrial events for the entire day. The abscissa represents time in $15-\mathrm{msec}$ units for a total of $750 \mathrm{msec}$ in a trial, and the ordinate represents the total count of units in those periods. The top trace above each histogram represents the averaged NM movement for an entire day, with up representing NM extension across the cornea. The first dotted vertical line of each histogram indicates CS onset, and the second dotted vertical line indicates UCS onset. (Reproduced with permission from McCormick, Clark, et al., 1982.) 


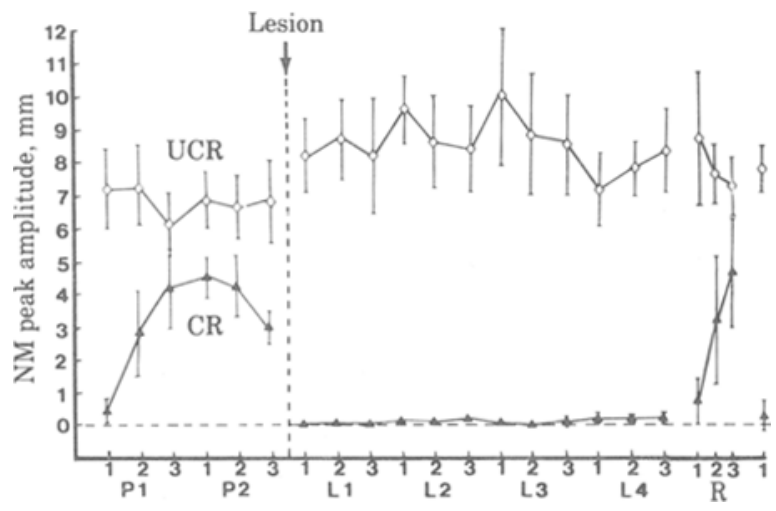

Figure 2. Averaged performances of rabbits $(N=5)$ first trained for the NM/eyelid response (P1 and P2), given a lesion of the left cerebellum and recovery, then retrained for 4 days on the left eye (L1-L4) without showing any CRs but with UCR performance normal, trained on the right eye (uninjured side) with rapid learning, and finally switched back to the left eye without learning. The abscissa is divided into successive units of $1 / 3$ of a day of training; the ordinate represents averaged peak $\mathrm{NM}$ amplitude in millimeters. (Reproduced with permission from McCormick, Clark, et al., 1982.)

of the appropriate region of the red nucleus abolish the conditioned response but can cause motor impairment of the unconditioned response as well, although the latter effect appears transient (Haley et al., 1983). Pharmacological intervention in the red nucleus with picrotoxin, however, abolishes only the learned response (Madden, Haley, Barchas, \& R. F. Thompson, 1983). Thus, the motor circuit for the learned response involves the cerebellum and its traditional output pathway through the superior cerebellar peduncle and the contralateral red nucleus. The red nucleus then projects contralaterally via the descending rubral pathways to the cranial motor nuclei and/or reflex pathways (e.g., Courville, 1966a, 1966b).

Theories of the role of the cerebellum in motor learning stress the cytoarchitecture of the cerebellar cortex (Albus, 1971; Eccles, Ito, \& Szentagothai, 1967; Ito, 1970; Marr, 1969). Our recording results to date suggest that the cerebellar cortex may indeed be involved in the production of the learned response and may play an important role in initial learning of the CR. However, results of our lesion studies to date indicate that the cerebellar cortex is not essential for the memory of the learned NM/eyelid response. Although lesion deficits can provide strong evidence for identification of the circuitry essential for a conditioned response, they cannot demonstrate where the memory trace is, only where it is not. Thus, abolition of the CR by lesions of the cerebellum may result from destruction of the memory trace or destruction of a part of the essential circuitry for a memory trace located elsewhere. Other lines of evidence (see below) argue that the memory trace is either in the cerebellum or afferent to the cerebellum. Granting this for argu- ment's sake, if the trace is in the cerebellum, an effective lesion limited to the lateral interpositus nucleus could abolish a memory trace located in either the nucleus or in the cerebellar cortex, since relevant cerebellar cortex projects only to the interpositus. The fact that lesions of the part of the cerebellar cortex that projects to the critical region of the interpositus nucleus do not abolish the $C R$ argues that the memory trace is not in the cerebellar cortex (McCormick \& R. F. Thompson, 1984).

From several lines of evidence, we can argue that the critical tissue necessary for the CR is in the dorsolateral interpositus nucleus or in structures afferent to it for which it is a mandatory efferent. Recordings from this region show the unit-model of the behavior, electrolytic or aspirative lesions that do not involve this tissue (or the superior cerebellar peduncle), are ineffective, and stimulation of this region evokes an eyeblink response. Picrotoxin and bicuculine infused in this region abolish an already learned response (Mamounas, Madden, Barchas, \& R. F. Thompson, 1983). Several of us have noted that if a cannula placement itself damages this critical region, then the rabbit is incapable of initial learning. Chemical lesions of the critical dorsolateral interpositus made by kainic acid, presumed to spare fibers of passage from the dentate nucleus, also abolish the learned response (Lincoln, Lavond, Hembree, J. K. Thompson, \& R. F. Thompson, 1983). In current work using trace $\mathrm{NM}$ /eyelid conditioning rather than delay conditioning (CS on $250 \mathrm{msec}$, 500-msec no-stimulus trace interval, 100 -msec UCS), so that there is a greater memory demand on the organism (it takes approximately four to five times as many trials to learn), we have found no evidence that the cerebellar cortex is critical (Woodruff-Pak, Lavond, \& R. F. Thompson, 1984). Damage to the ipsilateral interpositus nucleus, however, abolished the trace conditioned response.

The nature of the deficit caused by interpositus lesions can be a motor deficit limited to the production of the learned response (i.e., memory trace afferent to interpositus) or due to destruction of the locus of the engram itself. Primary auditory impairments can be ruled out because rabbits with bilateral cerebellar lesions that cannot learn the NM/eyelid response on either side learn a heart-rate conditioned response as well as normal rabbits to the same frequency auditory CS (Lavond, Lincoln, McCormick, \& R. F. Thompson, in press). This is another argument against the notion that the lesion prevents learning by affecting nonspecific factors, that is, motivation. Control rabbits learn both responses in the same training sequence without any interference. This particular study also rules out the possibility that an asymmetrical lesion uniquely produces a behavioral deficit (Sprague, 1966).

An approach to determining where the plasticity occurs is to define completely the circuit for classical 
conditioning of the NM/eyelid response. Once this is known, then recordings along the entire circuit will identify the first locus of plasticity associated with learning. The effective airpuff UCS is critically dependent upon the dorsal accessory inferior olive (McCormick \& R. F. Thompson, 1983; Steinmetz, McCormick, Baier, \& Thompson, in press). Rabbits well trained on the delay paradigm and subsequently given lesions of this region (but no other) of the inferior olive appear to extinguish when retrained. That is, the animals initially show CRs when training is resumed after the lesion, but these become fewer and smaller with continued training and eventually extinguish. The part of the inferior olive that is critical for this effect also projects directly to the same area of the interpositus necessary for conditioning (Gibson, Houk, \& Robinson, 1983).

The auditory input to the cerebellum has been very difficult to determine, because the conventional method of electrolytic lesions of brainstem auditory structures often causes severe motor deficits, making interpretation difficult. Figure 3 provides an example of a new strategy that has allowed us to identify initially the necessary auditory pathway for conditioned responses (Lavond, Woodruff-Pak, \& R. F. Thompson, in press). Microcannulae were implanted bilaterally in the lateral lemniscus rostral to the cochlear nuclei. Animals were overtrained beyond the criterion of the $8 / 9 \mathrm{CRs}$ to a tone CS and then to a light CS. They were then injected with a local anesthetic (lidocaine) and tested to both CSs. Learned responses to the tone were abolished but remained intact to the light CS. There was no effect on the UCRs. CRs to tone recovered fully with continued training. Subsequent injection of ibotenic acid and a 1-week recovery time did not abolish the CRs to either CS. Histological examination showed complete destruction of neuron somas and extensive gliosis at the sites of injection due to the ibotenic acid. In this manner, we have initially identified the necessary tone pathway as involving the lateral lemniscus. Alternative routes of tone information from the cochlear nuclei (i.e., direct projection to cerebellar vermis; C. Huang, Liu, \& R. Huang, 1982) cannot support CRs. The inferior colliculus can be ruled out, because bilateral infusions of up to $7 \mu \mathrm{l}$ of lidocaine per colliculus had no effect at all on performance of the CR to tone, consistent with unpublished observations in our laboratory, where the inferior colliculus was ablated bilaterally by aspiration.

A major lesson to be learned from the recoveryof-function literature is that behaviors that appear to be abolished are not always abolished permanently (cf. Bach-y-Rita, 1980; Cotman, 1978; Finger, 1978; Isaacson \& Spear, 1982; Miller, Sandman, \& Kastin, 1977; Stein, Rosen, \& Butters, 1974; Walsh \& Greenough, 1976). Behaviors can often be reestablished with extensive retraining, drug injections, interopera-

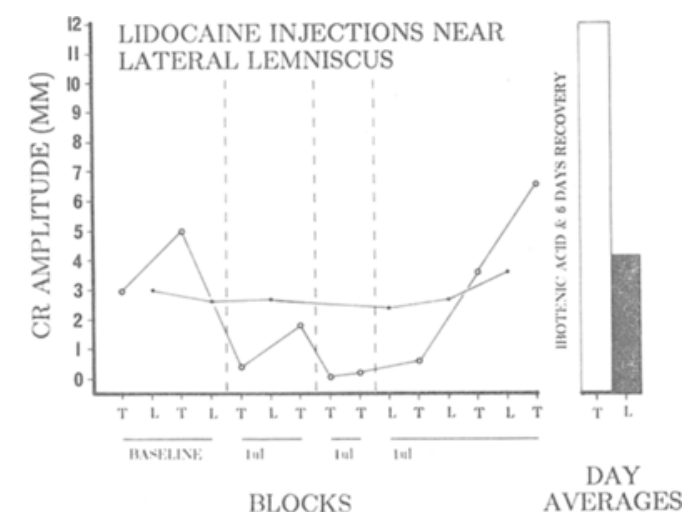

Figure 3. After having been overtrained on alternating eight-trial blocks of tone or light CSs, the rabbit in this figure was tested first with four baseline blocks and then given $1 \mu$ of lidocaine injected into each lateral lemniscus. The CRs to tone $C S$ were completely abolished. The rabbit was again injected with $1 \mu \mathrm{l}$ of lidocaine. On the next tone-then-light blocks, the rabbit had no CRs to tone CS but continued to show CRs to light CS. Giving $1 \mu \mathrm{l}$ more and a light-then-tone sequence produced the same results. The CR to tone $\mathrm{CS}$ recovered over continued training. The lidocaine effects of this rabbit are typical of those of three other rabbits. This rabbit was then injected with ibotenic acid in order to destroy cell bodies but spare fibers of passage, and allowed 6 days of recovery. When retested, the rabbit showed CRs to both tone and light CSs, also typical of the other three rabbits tested. (The very large CRs to tone seen after ibotenic acid injection are not typical of the other three rabbits.) These results indicate that lidocaine affected a critical auditory pathway. The abscissa represents blocks of eight trials to either tone (T) or light (L) CS, and the ordinate represents averaged $\mathrm{CR}$ amplitude.

tive retraining (e.g., D. R. Meyer \& P. M. Meyer, 1977 , in press). In the studies mentioned so far, we retrained the rabbits for 2 to 5 times as many training trials as was necessary to initially learn and found no signs of recovery of function.

More recently we have studied the effects of cerebellar lesions over longer periods of time. Figure 4 depicts the results of a rabbit that had been initially trained on NM/eyelid conditioning on both eyes, then was given bilateral radical cerebellar ablations, which included the interpositus nucleus, and tested for retention after 1 week, 1 month, and 3 months following the lesion. As can be seen in the figure, before the lesion, the rabbit learned on the right very rapidly following normal learning on the left. After the cerebellar aspiration, the rabbit did not retain the habit when tested on the left for 4 days and then on the right for 4 days. Note that the right eye gave a few small CRs and that the right cerebellar lesion was less complete than the left lesion. However, with repeated retraining at 1 month and then at 3 months, even this indication of minimal retention vanished. There is no recovery of function-in fact, there is just the opposite.

In a recently completed study of long-term training depicted in Figure 5, we periodically trained bi- 


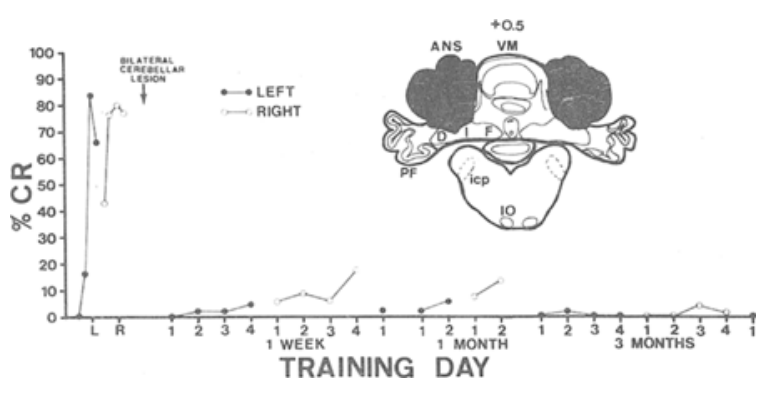

Figure 4. Percentage of CRs shown by one rabbit first trained on the left and right eyes for the NM/eyelid response, lesioned bilaterally, and then tested at intervals of 1 week (4 days of training on each the left and right eyes plus 1 more day on the left), 1 month (2 days on each eye), and 3 months (4 days on left and right eyes, 1 more day on the left) following the lesion without recovering from the deficit. The histology shows that the dorsolateral part of the interpositus nucleus has been destroyed. (Reproduced with permission from Lavond, Lincoln, McCormick, \& Thompson, in press).

laterally lesioned rabbits (electrolytic lesions to medial dentate-lateral interpositus nuclear region) for over half a year. During this time, they showed no signs of acquiring the habit. (We determined that these rabbits were not deaf because they gave normal orienting responses to auditory stimuli.) The control animal (cerebellar cortical aspiration) learned and retained very well over the same period. At the end of this period, we also tested these animals with am- phetamine ( $1 \mathrm{mg} / \mathrm{kg}$ of d-amphetamine), a treatment that has been reported to enhance some recoveries (Braun, P. M. Meyer, \& D. R. Meyer, 1966; Jonason, Lauber, Robbins, P. M. Meyer, \& D. R. Meyer, 1970; P. M. Meyer, 1963; P. M. Meyer, Horel \& D. R. Meyer, 1963), but to no avail. Destruction of the interpositus nucleus, therefore, seems to abolish permanently the recall or establishment of classical conditioning of the NM/eyelid response. (These same animals were trained on and successfully learned operant tasks before and after lesion; Holt, Mauk, \& R. F. Thompson, 1984.) The effect is not limited to the NM/eyelid response, because the same treatment will abolish a classically conditioned hindlimb flexion response as well when the interpositus lesion extends more medially (Donegan, Lowrey, \& R. F. Thompson, 1983). These findings agree with earlier ones in the Russian literature, which have reported that completed cerebellectomy impairs or abolishes the leg-flexion conditioned response (Gambaryn, 1960; Karamian, Fanardijian, \& Kosareva, 1960; Popov, 1929) as well as salivary conditioned responses (Krasusky, 1957; Lifshitz, 1947). We suspect that any classically conditioned somatic response, at least those learned with an aversive UCS, will be abolished by appropriate lesion of the deep nuclei of the cerebellum.

Our finding that lesions limited to as little as $1 \mathrm{~mm}^{3}$ of cellular tissue in the brain selectively and per-

\section{LONG-TERM TRAINING AND AMPHETAMINE TREATMENT}

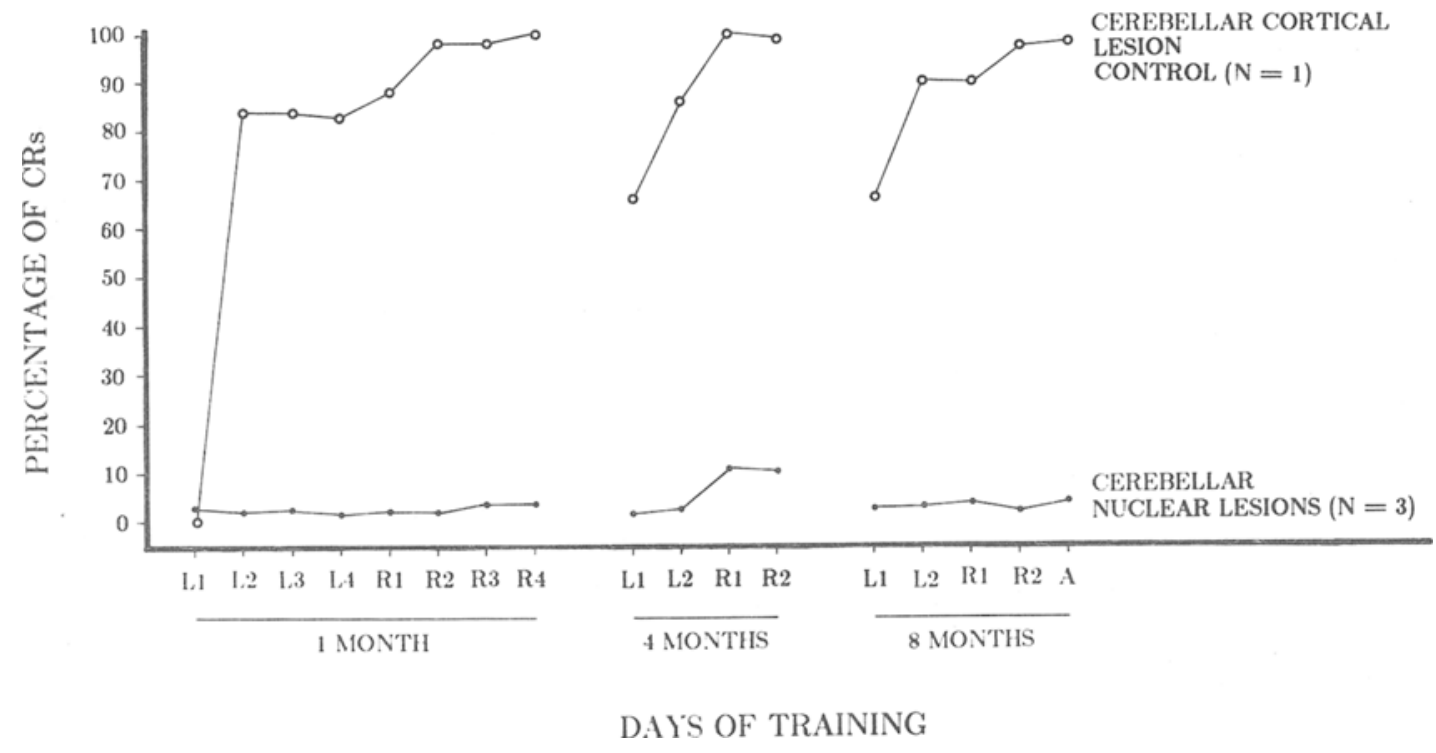

Figure 5. Following bilateral electrolytic lesions of the interpositus nucleus $(\mathrm{N}=3)$ and cerebellar cortical aspiration $(\mathrm{N}=1$ ), the rabbits were trained for $\mathrm{NM}$ /eyelid conditioning after 1 month of recovery ( 4 days of training on both eyes), after more than 4 months of recovery ( 2 days of training on both eyes), and after more than $8 \frac{1}{2}$ months of recovery ( 2 days of training on both eyes). Only the cortical control animal learned and retained over this period. All rabbits were subsequently treated with amphetamine (1 day of training on the left eye) without improving or impairing their previous performances. These same rabbits were trained on operant tasks before and after the lesions (these results, as well as histology, will be reported by Holt, Mauk, and Thompson, in a paper now in preparation). 
manently abolish a learned response (kainic acid interpositus lesion result; Lincoln et al., 1983) is perhaps unique in the brain-damage learning literature. Following such highly localized lesions, the animals never show any signs of recovery-of learning or relearning the conditioned response-and at the same time show no impairments in motor performance, sensory perception, or more general phenomena such as "attention" or "motivation." Why is our result so different from the rest of the recovery-of-function literature? We suggest the reason is because we have succeeded in localizing the essential memory trace circuit for the learned response, and it is extraordinarily localized.

Many lesions cause a transient decrease in conditioned NM/eyelid responding-for example, neodecortication (Oakley \& Russell, 1972) or removal of a limited region of cerebellar cortex (in the trace paradigm, Woodruff-Pak et al., 1984). Such lesion effects might be described as "deficits" and be said to show "recovery of function," but they do so because the structures damaged are not a part of the essential memory trace circuit. Such transient deficits may be due to "nonspecific" lesion effects (neodecortication appears to be an example of this), or because the structure damaged may normally play a role but is not essential (cerebellar cortex may be an example of this). Indeed, these are among the many hypotheses proposed to account for recovery of function (e.g., diaschisis, vicariation, neural stability). However, there are recovery-of-function effects that cannot be so simply explained (D. R. Meyer \& P. M. Meyer, 1977, in press). In the discussion that follows, we focus on an alternative possibility involving essential memory trace systems.

Let us assume, for the sake of argument, that all memory trace circuits in the brain are highly localized. A given task may have more than one memory-trace circuit, each highly localized, each pathway coding and storing a different aspect of the stimulus/task (cf. Hunter, 1930). For example, there appear to be three parallel visual pathways involved in heart-rate conditioning in the pigeon (Cohen, 1980). A lesion of any one or two of such parallel circuits could produce an apparent lack of localization because of surviving parallel circuits with redundant or sufficiently similar functions. The stimuli used in visual discrimination training are usually parsed into two categories, brightness and form, but recent data suggest a possible alternative parsing into two visual "systems," one particularly sensitive to brightness and high spatial frequencies and another which is relatively insensitive to brightness and high spatial frequencies but very sensitive to the locations of objects in space (Leibowitz \& Post, 1982; Schneider, 1969). Thus, stimuli used in visual discrimination tasks that activate both of these hypothetical systems could result in individual memory traces for different aspects of the visual stimulus. (Additional traces are probably formed as well, as between response and reinforcement, context and outcomes, etc., but here we consider only the visual traces.) If each is, in fact, essential for its aspect of the visual stimulus, each would participate in the discrimination learning task, and damage to either could easily cause impairment followed by recovery of function.

The general notion of "multiple traces" is, of course, not new (Hebb, 1949). We suggest that each trace codes a different aspect of the stimulus/task, rather than multiple representations of the same trace. A strong prediction from this suggestion is that if it is possible to use visual stimuli that selectively activate one or the other of these hypothetical visual systems, then it should be possible, with appropriate lesions, to abolish one or the other visual discrimination selectively and permanently with no recovery of function (see Lavond \& Dewberry, 1980, for a possible example). In more general terms, it may be that recovery of some functions is due to the brain's parsing of stimuli and tasks in ways that are different from those used by psychologists, for it is not at all clear that we yet know what these "natural" categories are.

In sum, in the past few years we have discovered the essential neuronal circuit necessary for producing the learned response in classical conditioning of the $\mathrm{NM} /$ eyelid and leg-flexion in the rabbit. We have yet to identify completely the CS and UCS pathways, and therefore have not unequivocally established the locus within the circuit for the neuronal plasticity, the "engram," responsible for this basic form of conditioning. However, it now appears that solution of the problem is feasible. Once the locus has been determined, it will then be possible to analyze the actual neuronal/synaptic mechanisms involved in this form of learning. Mechanisms underlying more complex types of learning may then be more accessible for study.

\section{REFERENCES}

AlBus, J. S. (1971). A theory of cerebellar function. Mathematical Biosciences, 10, 25-61.

BACH-Y-RITA, P. (Ed.) (1980). Recovery of function: Theoretical considerations for brain injury rehabilitation. Vienna: Huber.

Braun, J. J., Meyer, P. M., \& Meyer, D. R. (1966). Sparing of a brightness habit in rats following visual decortication. Journal of Comparative and Physiological Psychology, 61, 79-82.

Clark, G. A., McCormick, D. A., Lavond, D. G., Baxter, K. Gray, J., \& Thompson, R. F. (1982). Effects of electrolytic lesions of cerebellar nuclei on conditioned behavioral and hippocampal responses. Neuroscience Abstracts, 8, 22.

Clark, G. A., McCormick, D. A., Lavond, D. G., \& Thompson, R. F. (1984). Effects of lesions of cerebellar nuclei on conditioned behavioral and hippocampal neuronal responses. Brain Research, 291, 125-136.

CoHen, D. H. (1980). The functional neuroanatomy of a conditioned response. In R. F. Thompson, L. H. Hicks, \& V. B. 
Shvyrlov (Eds.), Neuronal mechanisms of goal-directed behavior and learning (pp. 283-302). New York: Academic Press.

Cotman, C. W. (Ed.) (1978). Neuronal plasticity. New York: Raven Press.

Courville, J. (1966a). Rubrobulbar fibers to the facial nucleus and the lateral reticular nucleus (nucleus of the lateral funiculus): An experimental study in the cat with silver impregnation methods. Brain Research, 1, 317-337.

Courville, J. (1966b). Somatotopical organization of the projection from the nucleus interpositus anterior of the cerebellum to the red nucleus: An experimental study in the cat with silver impregnation methods. Experimental Brain Research, 2, 191-215.

Donegan, N. H., Lowry, R. W., \& Thompson, R. F. (1983). Effects of lesioning cerebellar nuclei on conditioned leg-flexion responses. Neuroscience Abstracts, 9, 331.

Eccles, J. C., Ito, M., \& Szentagothai, J. (1967). The cerebellum as a neuronal machine. New York: Springer-Verlag.

ENSER, L. D. (1976). A study of classical nictitating membrane conditioning in neodecorticate, hemidecorticate and thalamic rabbits. Unpublished doctoral dissertation, University of Iowa.

Finger, S. (Ed.) (1978). Recovery from brain damage: Research and theory. New York: Plenum Press.

GAMBARYN, L. S. (1960). Conditioned avoidance reflexes induced in dogs with cerebellar lesions. Physiologia Bohemoslovenica, 9, 261-266.

Gibson, A. R., Houk, J. C., \& Robinson, F. R. (1983). Climbing fiber projections from physiologically identified areas of the cat dorsal accessory olive. Neuroscience Abstracts, 9, 869.

Gormezano, 1. (1972). Classical conditioning: Investigations of defense and reward conditioning in the rabbit. In A. H. Black \& W. F. Prokasy (Eds.), Classical conditioning II. New York: Appleton-Century-Crofts.

Gormezano, I., Schneiderman, N., Deaux, E., \& Fuentes, I. (1962). Nictitating membrane: Classical conditioning and extinction in the albino rabbit. Science, 138, 33-34.

Haley, D. A., Lavond, D. G., \& Thompson, R. F. (1983). Effects of contralateral red nuclear lesions on retention of the classically conditioned nictitating membrane/eyelid response. Neuroscience Abstracts, 9, 643

Невв, D. O. (1949). Organization of behavior. New York: Wiley.

Holt, L., MaUk, M. D., \& Thompson, R. F. (1984). Effects of lateral cerebellar lesions on classical and operant conditioning. Unpublished manuscript.

Huang, C., Liv, G., \& Huang, R. (1982). Projections from the cochlear nucleus to the cerebellum. Brain Research, 244, 1-8.

HunTER, W. S. (1930). A consideration of Lashley's theory of the equipotentiality of cerebral action. Journal of Genetic Psychology, 3, 455-468.

IsaAcson, R. I., \& Spean, N. E. (Eds.) (1982). The expression of knowledge. New York: Plenum Press.

ITo, M. (1970). Neurophysiological aspects of the cerebellar motor control system. International Journal of Neurology, 7, 162-176.

Jonason, K. R., Lauber, S. M., Robeins, M. J., Meyen, P. M., \& MEYER, D. R. (1970). Effects of amphetamine upon relearning pattern and black-white discriminations following neocortical lesions in rats. Journal of Comparative and Physiological Psychology, 73, 47-55.

Karamian, A. I., Fanardijian, V. V., \& Kosareva, A. A. (1960). The functional and morphological evolution of the cerebellum and its role in behavior. In R. Llinas (Ed.), Neurobiology of cerebellar evolution and development, First International Symposium. Chicago: American Medical Association.

KrasusKY, V. K. (1957). General nature of changes of food conditioned reflexes in dogs following surgical lesion of the cerebellum. Zh. vyssh. nerv. Deyat. I.P. Pavlova, 7, 733-740.

LAShlEY, K. S. (1950). In search of the engram. In Symposium of Social and Experimental Biology (vol. 4, pp. 454-482). New York: Cambridge University Press.

Lavond, D. G., \& DewberRY, R. G. (1980). Visual form perception is a function of the visual cortex: II. The rotated horizontal- vertical and oblique-stripes pattern problems. Physiological Psychology, 8, 1-8.

Lavond, D. G., Lincoln, J. S., McCormick, D. A., \& Thом Pson, R. F. (1983). Effect of bilateral cerebellar lesions on heart-rate and nictitating membrane/eyelid conditioning in the rabbit. Neuroscience Abstracts, 9, 636 .

Lavond, D. G., Lincoln, J. S., McCormick, D. A., \& Thompson, R. F. (in press). Effect of bilateral lesions of the dentate and interpositus cerebellar nuclei on conditioning of heart-rate and nictitating membrane/eyelid responses in the rabbit. Brain Research.

Lavond, D. G., McCormick, D. A., Clark, G. A., Holmes, D. A., \& Thompson, R. F. (1981). Effects of ipsilateral rostra pontine reticular lesions on retention of classically conditioned rabbit nictitating membrane responses. Physiological Psychology, 9, 335-339.

Lavond, D. G., Woodnuff-Pak, D. S., \& Thompson, R. F. (in press). Initial identification of the essential brainstem auditory pathway necessary for classical conditioning of the rabbit nictitating response. Neuroscience Abstracts.

Leibowitz, H. W., \& Post, R. B. (1982). The two modes of processing concept and some implications. In J. Beck (Ed.), Organization and representation in perception (pp. 343-363). Hillsdale, NJ: Erlbaum.

Lifshitz, N. N. (1947). Influence of the cerebellar ablation on conditioned reflexes in dogs. Trudy fiziol. Inst. Pavlova Acad. Sci, 2, 11-50.

Lincoln, J. S., Lavond, D. G., Hembree, T. L., Thompson, J. K., \& Thompson, R. F. (1983). Effect of kainic acid lesions of the cerebellar nuclei on nictitating membrane/eyelid conditioning and an HRP demonstration of cerebellar afferents. Neuroscience Abstracts, 9, 636.

Lincoln, J. S., McCormick, D. A., \& Thompson, R. F. (1982) Ipsilateral cerebellar lesions prevent learning of the classically conditioned nictitating membrane/eyelid response. Brain $\mathbf{R e}$ search, 242, 190-193.

Madden, IV, J., Haley, D. A., Barchas, J. D., \& Thompson, R. F. (1983). Microinfusion of picrotoxin into the caudal red nucleus selectively abolishes the classically conditioned nictitating membrane/eyelid response in the rabbit. Neuroscience Abstracts, 9,830 .

Mamounas, L. A., Madden, J., IV, Bahchas, J. D., \& Thompson, R. F. (1983). Microinfusion of GABA antagonists into the cerebellar deep nuclei selectively abolishes the classically conditioned eyelid response in the rabbit. Neuroscience Abstracts, 9, 830.

MARR, D. (1969). A theory of cerebellar cortex. Journal of Physiology (London), 202, 437-470.

MoCormick, D. A., Clark, G. A., Lavond, D. G., \& Thompson, R. F. (1982). Initial localization of the memory trace for a basic form of learning. Proceedings of the National Academy of Sciences, 79, 2731-2735.

McCormick, D. A., Guyer, P. E., \& Thompson, R. F. (1982) Superior cerebellar peduncle lesions abolish the ipsilateral classically conditioned nictitating membrane/eyelid response of the rabbit. Brain Research, 245, 347-350.

McCormick, D. A., Lavond, D. G., Clark, G. A., Kettiner, R. E., Rising, C. E., \& Thompson, R. F. (1981). The engram found? Role of the cerebellum in classical conditioning of nictitating membrane and eyelid responses. Bulletin of the Psychonomic Society, 18, 103-105.

McCormick, D. A., Lavond, D. G., Donegan, N. H., \& Thompson, R. F. (1982). Neuronal responses of the rabbit brainstem and cerebellum during performance of the classically conditioned nictitating membrane/eyelid response. Neuroscience Abstracts, 8, 315.

McCormick, D. A., Lavond, D. G., \& Thompson, R. F. (1982). Concomitant classical conditioning of the rabbit nictitating membrane and eyelid responses: Correlations and implications. Physiology \& Behavior, 28, 769-775. 
McCormick, D. A., Lavond, D. G., \& Thompson, R. F. (1983). Neuronal responses of the rabbit brainstem during performance of the classically conditioned nictitating membrane (NM)/ eyelid response. Brain Research, 271, 73-88.

McCormick, D. A., \& Thompson, R. F. (1983). Possible neuronal substrate of classical conditioning within the mammalian CNS: Dentate and interpositus nuclei. Neuroscience Abstracts, 9, 643.

McCormick, D. A., \& Thompson, R. F. (1984). Cerebellum: Essential involvement in the classically conditioned eyelid response. Science, 223, 296-299.

Meyer, D. R., \& MEYER, P. M. (1977). Dynamics and bases of recoveries of functions after injuries to the cerebral cortex. Physiological Psychology, 5, 133-165.

Meyen, D. R., \& Meyer, P. M. (in press). Bases of recoveries from perinatal injuries to the cerebral cortex. In S. Finger \& C. R. Almli (Eds.), The behavioral biology of early brain damage. New York: Academic Press.

MeYer, P. M. (1963). Analysis of visual behavior in cats with extensive neocortical ablations. Journal of Comparative and Physiological Psychology, 56, 397-401.

Meyer, P. M., Horel, J. A., \& Meyer, D. R. (1963). Effects of dl-amphetamine upon placing responses in neodecorticate cats. Journal of Comparative and Physiological Psychology, 56, 402-404.

Mille R, L. H., Sandman, C. A., \& Kastin, A. J. (Eds.) (1977). Neuropeptide influences of brain and behavior. New York: Raven Press.

Norman, R., Villablanca, J. R., Brown, K. A., Schwafel, J. A., \& Buchwald, J. S. (1974). Classical conditioning in the bilateral hemispherectomized cat. Experimental Neurology, 44, 363-380.

OAKley, D. A., \& Russell, I. S. (1972). Neocortical lesions and classical conditioning. Physiology \& Behavior, 8, 915-926.

Popov, N. F. (1929). The role of the cerebellum in elaborating the motor conditioned reflexes. In Higher nervous activity. Moscow: Com. Acad. Press.

Schneide R, G. E. (1969). Two visual systems. Science, 163, 895-905.

Sprague, J. M. (1966). Interaction of cortex and superior colliculus in mediation of visually guided behavior in the cat. Science, 153, 1544-1547.

Stein, D. G., Rosen, J. J., \& Butters, N. (Eds.) (1974). Plasticity and recovery of function in the central nervous system. New York: Academic Press.

Steinmetz, J. E., McCormick, D. A., Baier, C. A., \& Thompson, R. F. (in press). Involvement of the inferior olive in classical conditioning of the rabbit eyelid. Neuroscience Abstracts.

Thompson, R. F., Berger, T. W., Cegavske, C. F., Patterson, M. M., Roemer, R. A., Teyler, T. J., \& Young, R. A. (1976). The search for the engram. American Psychologist, 31, 209-227.

Walsh, R. N., \& Greenough, W. T. (Eds.) (1976). Advances in behavioral biology: Environments as therapy for brain dysfunction (Vol. 17). New York: Plenum Press.

Woodruff-Pak, D. S., Lavond, D. G., \& Thompson, R. F. (in press). Cerebellar anisform cortex aspiration does not abolish trace conditioning in the rabbit. Neuroscience Abstracts.

Yeo, C. H., Hardiman, M. J., Glickstein, M., \& Russell, I. S. (1982). Lesions of cerebellar nuclei abolish the classically conditioned nictitating membrane response. Neuroscience Abstracts, $8,22$.

(Manuscript received May 18, 1984; revision accepted for publication May 23, 1984.) 